\title{
Factors of Group Design Decision Making
}

\section{Mr. Andrew Jackson, Purdue University, West Lafayette}

Andrew Jackson is currently pursuing a Master of Science in Technology Leadership and Innovation in Purdue University's College of Technology. His previous middle school teaching experience informs his role as a graduate teaching assistant for an introductory course in design thinking. His research interests are engineering self-efficacy, creativity, and decision making.

\section{Prof. Nathan Mentzer, Purdue University, West Lafayette}

Nathan Mentzer is an assistant professor in the College of Technology with a joint appointment in the College of Education at Purdue University. Hired as a part of the strategic P12 STEM initiative, he prepares Engineering/Technology candidates for teacher licensure. Dr. Mentzer's educational efforts in pedagogical content knowledge are guided by a research theme centered in student learning of engineering design thinking on the secondary level. Nathan was a former middle and high school technology educator in Montana prior to pursuing a doctoral degree. He was a National Center for Engineering and Technology Education (NCETE) Fellow at Utah State University while pursuing a Ph.D. in Curriculum and Instruction. After graduation he completed a one year appointment with the Center as a postdoctoral researcher.

\section{Dr. Angelika N Zissimopoulos, Purdue University, West Lafayette}

Dr. Zissimopoulos holds a PhD in Biomedical Engineering From Northwestern University. She is currently an Instructional Developer at the Center for Instructional Excellence at Purdue University and works extensively with course design and faculty development. She also holds a courtesy appointment with the College of Technology. 


\section{Factors of Group Design Decision Making}

Background Effective decision making is a hallmark of experienced designers. The decision process is complicated by working in groups because multiple viewpoints need to be considered and each member may possess different information relevant to the decision. Subsequently, a structure to evaluate the decision-making process is needed.

Purpose/Hypothesis The purpose of this study was to develop an instrument to evaluate quality of group design decision making.

Design/Method The instrument development process presented here includes a definition of and organization for content relevant to group decision making, external review of the survey instrument, and two administrations used to establish the factorial validity of the instrument. Exploratory and confirmatory factor analysis was used to test the factor structure.

Results Evidence supports the reliability and initial validity of the 14-item decision-making instrument. Three reliable latent constructs are present which support effective decision making: Processing Information, Understanding Decisions, and Processing Alternatives (Cronbach's $\alpha$ : $.90, .84$, and .88). A first-order factor structure produced a good fitting model, $\chi^{2}=272.412, \mathrm{p}<$ $.001 ;$ RMSEA $=.072 ; \mathrm{CFI}=.983 ; \mathrm{GFI}=.927$. A second-order model also had good fit, $\chi^{2}=$ $275.034, \mathrm{p}<.001 ; \mathrm{RMSEA}=.072 ; \mathrm{CFI}=.983 ; \mathrm{GFI}=.927$.

Conclusions The decision-making instrument appears to measure group decision-making processes and may be used by practitioners to guide instruction. Future research should continue to assess the validity of the instrument and may use a parsimonious second-order construct to do so.

\section{Introduction}

Engineering design is a decision-making process. ${ }^{1-4}$ Designers make decisions among alternative solutions, decisions about feasibility of individual solutions, and decisions about narrowing or broadening the problem scope. ${ }^{5}$ They also make logistical decisions about when teams will meet and how design decisions will be made. The ability to make these decisions is a critical skill for future engineers. ${ }^{6,7}$ Recent analysis of high school design groups ${ }^{8}$ revealed that beginning designers spent little time on decision processes, even in groups where the design outcomes may need to be negotiated. "Evaluation and decision making activities were rarely observed. Student teams spent very little time comparing alternatives on a criterion.... Students also spent very little time choosing among the alternatives" (p. 68). ${ }^{8}$ The minimal time spent interacting with alternatives while making decisions is a troubling indication of the ineffectiveness of student design decision making. ${ }^{9}$ Individual decision making has also been sparsely observed in samples ranging from high school freshmen to undergraduate seniors ${ }^{10-12}$ and we speculate that freshmen design teams similarly lack appropriate skills in effective design decision making.

The freshman level "Design Thinking in Technology" course is required for all students in the Purdue University College of Technology. In the course, students participate in three design 
activities which scale up in complexity; each experience provides greater depth of understanding in the steps of design and builds upon prior knowledge. Through repeated practice with design challenges, students engage in developing solutions to real-world problems and develop confidence with design. The curriculum promotes efficiency with all phases of design, including effective decision-making strategies: course learning objectives include learning to "manage design projects," "develop project timelines," "gather, synthesize, and use information to drive decision making processes," and "apply strategies of ideation to develop novel and innovative solutions" (p. 4). ${ }^{13}$ Each of these objectives provides an opportunity for students to practice group decision making. In the past year, changes were made to the Design Thinking course to improve student approaches to decision making. For example, additions to the curriculum included instruction and practice using a decision matrix which aids in using quantitative evidence to compare multiple solutions and facilitates group discussions about the design decision. ${ }^{14}$ Successful modifications to the curriculum should result in more effective decisionmaking processes among student design groups.

The instructors, as researchers, attempted to measure the quality of student group decision processes in order to improve future instruction. Conclusions made about the effectiveness of curriculum improvements can only be as accurate as the instruments used to gather data. ${ }^{15}$ The evaluation instrument needed to meet several criteria: it should relate to group decision processes to reflect the collaboration required and it should align with the processes and outcomes of design. A comprehensive instrument to measure the quality of group design decision processes was not discovered. The purpose of this study was to develop an instrument that would effectively measure group design decision making to both inform researcher understanding of the design decision-making process and inform design education practice. Therefore, literature was reviewed to identify elements of effective group decisions and effective design teams as well as usable items from existing related instruments that could be compiled to form an evaluative tool. Using these questions and ones formed by the researchers, an instrument was developed to help evaluate group decision processes. DeVellis ${ }^{16}$ described this process of defining and reviewing the content as beginning steps in scale development, followed by expert review, administration, evaluation, and validation.

Through the creation of a reliable tool to measure group decision making, practitioners and researchers can chart the progress of decision making as a critical component of student design thinking. The necessity for evaluation of decision-making skills is reinforced by the frequency that decisions are made and documented during the design process. ${ }^{14}$ Additionally, this evaluative tool is important because effective decision making is seen as a hallmark of more experienced designers and an aim for design education. ${ }^{5}$ Decision making is important in educational and professional environments, and it frequently occurs in groups. ${ }^{17,18}$

\section{Effective Group Decisions}

An existing instrument that met the criteria of aligning with group decision processes as well as technology and engineering design processes was not identified so the two criteria of design decisions were researched separately. First, information about effective collaboration, especially in group decision making, was reviewed. A predominant theme was effective sharing of information within teams before the decision-making process. In an analysis of group decision

making in a business context, Dean and Sharfman ${ }^{19}$ identified "procedural rationality," or the 
extent to which a team gathers information and uses that information to make a decision, as an important construct of effective decision making. The authors stated that effective decisions are "likely to involve relatively complete information and knowledge of constraints" (p. 374) within the group, suggesting both a thorough information searching process, and collectively sharing information among group members. This communication is foundational for decision making because each group member may be performing different tasks and has gained different knowledge. "20 "A group's effectiveness in solving strategic problems depends in part on its abilities to identify, extract, and use its members' potential contributions [most effectively]" (p.745). ${ }^{21}$ Sharing information about the decision, and subsequently a common vision for the decision, leads to increased productivity from the team and has been correlated with decision effectiveness. $^{19,22}$

Based on research about effective group decisions, several questions were gathered relating to the effectiveness of a team's information processing when making design decisions. Dean and Sharfman ${ }^{19}$ formed five questions related to the group decision process which were adapted to fit the context of design decision making. For example, Dean and Sharfman asked "How extensively did the group look for information in making this decision?" and "How extensively did the group analyze relevant information before making a decision?" These questions were expanded based on information that might be acquired during the design process, such as key factors relevant to the decision. ${ }^{5}$

\section{Effective Design Decisions}

Although implied in group decision literature discussed previously, key elements emergent in patterns of effective design decisions include identifying constraints and criteria, building an understanding and rationale for decisions, and considering a variety of alternatives. Crismond and Adams ${ }^{5}$ identified "making and explaining knowledge-driven decisions" (p. 14) as an indication of informed design practice and shared several patterns of thinking that support informed design decisions: doing research, idea fluency, deep drawing and modeling, and balancing benefits and tradeoffs. These elements in design decision-making literature expanded the discussion on effective group design decision making.

\section{Identifying Constraints and Criteria}

While gaining an understanding of the design problem through thorough investigation, experienced designers will "attempt to identify key issues associated with the problem" (p. $24)^{5}$ - in other words, constraints and criteria are critical for defining the problem and guiding the decision process. Beginning designers may make decisions without clearly stating or solidifying the constraints and criteria. ${ }^{5}$ The selection of constraints and criteria relevant to the original design problem is an important topic of communication that will take place in effective design decision making teams.

\section{Building an understanding and rationale}

Arguably, one of the purposes of information sharing within team decisions is to build a unified understanding of the decision. In design, this understanding process may include sketching or modeling which informs designer understanding of the decisions and is an important 
communication medium in teams. ${ }^{5,23}$ An informed designer is able to give reasons for the design decisions based on knowledge that has evolved throughout the design process. Further, an important aspect of effective design is the ability to communicate the decisions, for which an understanding of the decision is requisite. ${ }^{24}$ Understanding can support two effective types of decision making: reasoning-based decisions, which are qualitative in nature, or value-based decisions that are quantitative. ${ }^{5}$

\section{Considering a variety of alternatives}

Design is a creative process that generates a variety of solutions to a problem. ${ }^{25}$ In the ideation phases of design thinking a variety of strategies are recommended in literature to produce a wealth of possible solutions; decision-making phases refine the diverse solutions through comparison to the constraints and criteria identified, as well as evaluation of the benefits and tradeoffs of each alternative. The chance to select from this pool of unique ideas is an important part of generating so many possibilities. ${ }^{2}$ Generating many ideas is an opportunity to receive input from every team member and hopefully leads to the development and consideration of the best possible alternative. It is important for designers to be able to move past first ideas because in design decision making, the more ideas the better. ${ }^{5,26}$ Detailing the benefits and tradeoffs of each solution can facilitate a group discussion and should lead to a more unified understanding of the decision.

\section{Themes and Organization}

Based on the themes present in literature on group decision processes and effective design decision, three factors were proposed for evaluation in the decision-making instrument. These were named Processing Information, Understanding Decisions, and Processing Alternatives by the researchers based on the themes from literature and the variables included. Processing information includes information searching and sharing within teams, as well as identification of the key elements in the design problem that will guide the decision. Understanding decisions relates to the group's collective understanding of the decisions and alternatives. It includes an ability to focus on most important information during the decision process and being able to give a rationale for the choice. Processing alternatives suggests that teams should generate and consider a variety of alternatives, and balance a discussion on the benefits and tradeoffs of each alternative.

\section{Methodology}

The instrument development process began by identifying questions related to processing information, understanding decisions, and processing alternatives in group decision making which could be adapted to the context of design decision making. The research team then created questions based on elements of effective design decision making suggested in literature. All questions were structured using 7-point Likert-type scales. For example, on the question "How frequently did your team share data relevant to the decision with everyone in the design team?" participants responded from 1-7 with anchors of "never" and "always." The initial efforts yielded a survey containing 18 questions on decision making processes that were reviewed for content validity. ${ }^{27}$ A postdoctoral researcher specializing in research design and methodology 
and a staff member in the Center for Instructional Excellence with a $\mathrm{PhD}$ in engineering were joined by three instructors of the course to evaluate the clarity and content of the items.

The instrument was delivered electronically and results were analyzed using exploratory factor analysis (EFA). Following the first administration, the survey questions were modified, added, or eliminated based on the results leading to a similar instrument with 14 questions that was administered to a larger sample and analyzed using confirmatory factor analysis (CFA).

\section{Participants}

The samples represented by this study were drawn from two semesters of participants in the "Design Thinking in Technology" course. The course was typically administered with 25 sections annually and with approximately 40 students per section. Sections typically met for 50 minutes per week and had a significant expectation for student work prior to class as part of a flipped and blended instructional approach. The flipped and blended classroom creates a hybrid learning environment including online material and face-to-face instruction; ${ }^{28,29}$ student groups were expected to meet in and out of class.

All students in the sections who responded to the course reflection were included in the study; this was possible because the data analyzed for this student were gathered as a normal educational practice (IRB Exempt) in the course and analyzed after grades were issued for each term. The survey was first administered for EFA in the Spring 2014 semester to a sample of 218 students. Of those participants, a majority were male, $78 \%$. Students reported their year in school as: $42 \%$ freshman, $38 \%$ sophomores, $14 \%$ juniors, and $6 \%$ seniors. Of those reporting race, $74 \%$ were White/Caucasian, 14\% Asian, 4\% Hispanic or Latino, 3\% Black or African American, and $5 \%$ reported being another race. Students were asked to answer the questions about their group interaction and decision-making processes throughout the final project. Team size on the final project varied from two to five students with an average team size of 3.4. Teams were selfselected by students and the specific design problem was also chosen by the student teams.

The revised survey, for CFA, was given to 541 students enrolled in the design thinking course in the Fall 2014 semester. The respondents were similar to the previous semester with $83 \%$ being male. Ethnic composition of the students was similar to the first administration; students identified themselves as: 72\% White/Caucasian, 14\% Asian, 5\% Hispanic or Latino, 4\% Black or African American, and 4\% of another ethnic origin. A greater percentage of students were freshman (69\%). Team sizes in the fall semester were greater, averaging 4.5 and some teams had six members. According to Worthington and Whittaker ${ }^{27}$, in factor analysis, "sample sizes of at least 300 are generally sufficient in most cases" (p. 817) and sample sizes greater than 150 are likely to be adequate when the data set contains a high ratio of participants to items. For purposes of this research method, both sample sizes were deemed adequate based on the work of Worthington and Wittaker. ${ }^{27}$

\section{Analysis}

\section{Exploratory Factor Analysis}

Data cleaning followed steps recommended by Tabachnick and Fidell. ${ }^{30}$ Because the data were gathered using questions compiled from other sources, the internal reliabilities of several 
hypothesized factors of the decision-making process were first measured using Cronbach's alpha. The items showed strong internal reliability for each theorized factor of decision making $(\alpha>$.699) suggesting that it was appropriate to proceed with further analysis.

Using EFA the model was refined by removing problematic items such as items without significant loadings or items that loaded on the incorrect factor. Initially factors were retained following Kaiser's criterion to keep only factors with eigenvalues of greater than 1; however the resulting pattern matrix was unclear. Following recommendations in literature, decisions for factor retention were made on the basis of the multiple tests including the scree test, percentage of variance explained in total and by each factor, and conceptual interpretability. ${ }^{27,31}$ A clear 14item model was produced using principle axis factoring with Promax rotation and constraining the analysis to include three factors. The model explained $62 \%$ of the variation in the items and each factor has strong internal consistency, $\alpha=.901, \alpha=.836$, and $\alpha=.882$. These results show initial promise for the new survey instrument for measuring design decision processes of these three factors: Processing Information, Understanding Decisions, and Processing Alternatives. Each item loads well on the factor with only one item weakly cross-loading (see Table 1); the ambiguity of the cross-loading question indicated an opportunity for further clarification and discrimination in subsequent versions of the instrument.

Table 1. Pattern Matrix for EFA using principal axis factoring and Promax rotation.

\begin{tabular}{|c|c|c|c|}
\hline & \multicolumn{3}{|c|}{ Factors } \\
\hline & $\begin{array}{l}\text { Processing } \\
\text { Information } \\
(\alpha=.90)\end{array}$ & $\begin{array}{c}\text { Understanding } \\
\text { Decisions } \\
(\alpha=.84)\end{array}$ & $\begin{array}{c}\text { Processing } \\
\text { Alternatives } \\
(\alpha=.88)\end{array}$ \\
\hline $\begin{array}{l}\text { Did your group extensively analyze relevant information } \\
\text { before making a decision? }\end{array}$ & .835 & & \\
\hline $\begin{array}{l}\text { Did your group look extensively for information in making } \\
\text { these decision? }\end{array}$ & .779 & & \\
\hline Did your group use these factors to make your decision? & .706 & & \\
\hline $\begin{array}{l}\text { Did your group document the factors (using a decision } \\
\text { matrix or other tool)? }\end{array}$ & .639 & & \\
\hline $\begin{array}{l}\text { Did your group determine factors most important to the } \\
\text { decision? }\end{array}$ & .605 & & \\
\hline $\begin{array}{l}\text { The group was effective at focusing its attention on crucial } \\
\text { information and ignoring irrelevant information. }\end{array}$ & & .793 & \\
\hline My team can give a clear explanation for our decisions. & & .778 & \\
\hline $\begin{array}{l}\text { Quantitative analytic techniques (such as a decision matrix) } \\
\text { were important for our group in making these decisions. }\end{array}$ & & .641 & \\
\hline $\begin{array}{l}\text { I am satisfied with the way that these decisions were } \\
\text { reached. }\end{array}$ & & .618 & \\
\hline Did your group collectively make decisions? & & .475 & \\
\hline $\begin{array}{l}\text { Did your group look at the benefits of all alternative } \\
\text { solutions? }\end{array}$ & & & .890 \\
\hline $\begin{array}{l}\text { Did your group look at the tradeoffs of all alternative } \\
\text { solutions? }\end{array}$ & & & .705 \\
\hline $\begin{array}{l}\text { Did your group consider a variety of potential solutions } \\
\text { before deciding? }\end{array}$ & & & .686 \\
\hline $\begin{array}{l}\text { Did your group use a well-defined process to make these } \\
\text { decisions?* }\end{array}$ & .388 & & .453 \\
\hline
\end{tabular}

*The cross-loading question was revised to create two questions that aligned with each of the respective factors. 


\section{Confirmatory Factor Analysis}

Based on EFA, modifications and additions were made to the instrument items; the cross-loading indicator was reworded to discriminate between the two factors it was related to. The revised survey contained $14^{*}$ questions with three items that had been revised (see Error! Reference source not found. for the final survey). Data cleaning proceeded similar to the EFA phase of research with incomplete responses and unengaged cases being removed. Median substitution was used for missing values on Likert-type questions. ${ }^{32}$ Finally, correlations were reviewed for possible collinearity however no items showed significantly high correlation. ${ }^{30}$

Utilizing the previously obtained model, the factorial validity of the decision-making questionnaire was tested. The researchers predicted that: (a) indicators related to group decisionmaking processes would load appropriately on three factors (Processing Information, Understanding Decisions, and Processing Alternatives), (b) error terms would be uncorrelated, and (c) no items would cross-load. The factors were permitted to covary based on the hypothesis that they are related facets that constitute the overall decision process. The hypothesized model for the factorial structure of effective group design decision making is in Figure 1.

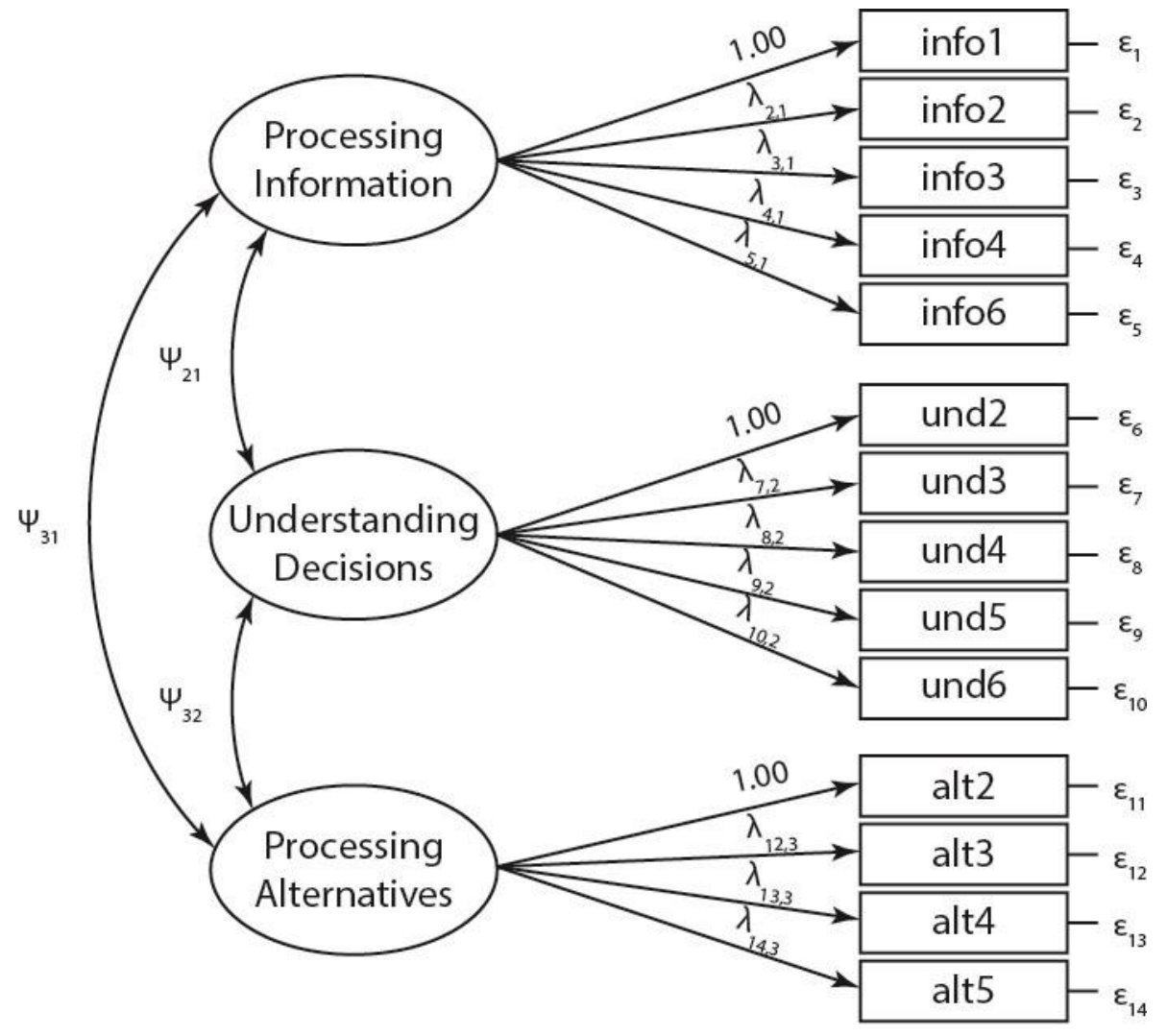

Figure 1. Hypothesized CFA Model for effective design decision making.

\footnotetext{
* An error during creation of the revised survey led to the omission of one question. The recommended instrument has 15 questions, however, the analysis detailed here includes only 14 items.
} 
The results for CFA showed that the measurement model was correctly specified in the syntax; it included the three factors with five items loading on each of the first two factors and four items loading on Processing Alternatives. All of the factor loading, factor covariance, and error estimates were significant. The goodness of fit indices showed that the model had good fit ${ }^{33}$ accounting for much of the variance among the indicators $\left(\chi^{2}=272.412, \mathrm{p}<.001\right.$; RMSEA $=$ .072 ; $\mathrm{CFI}=.983$; GFI $=.927)$. The model was maintained in favor of parsimony despite the modification indices reporting some potential changes to improve the fit of the model. The resulting measurement model is included in Figure 2.

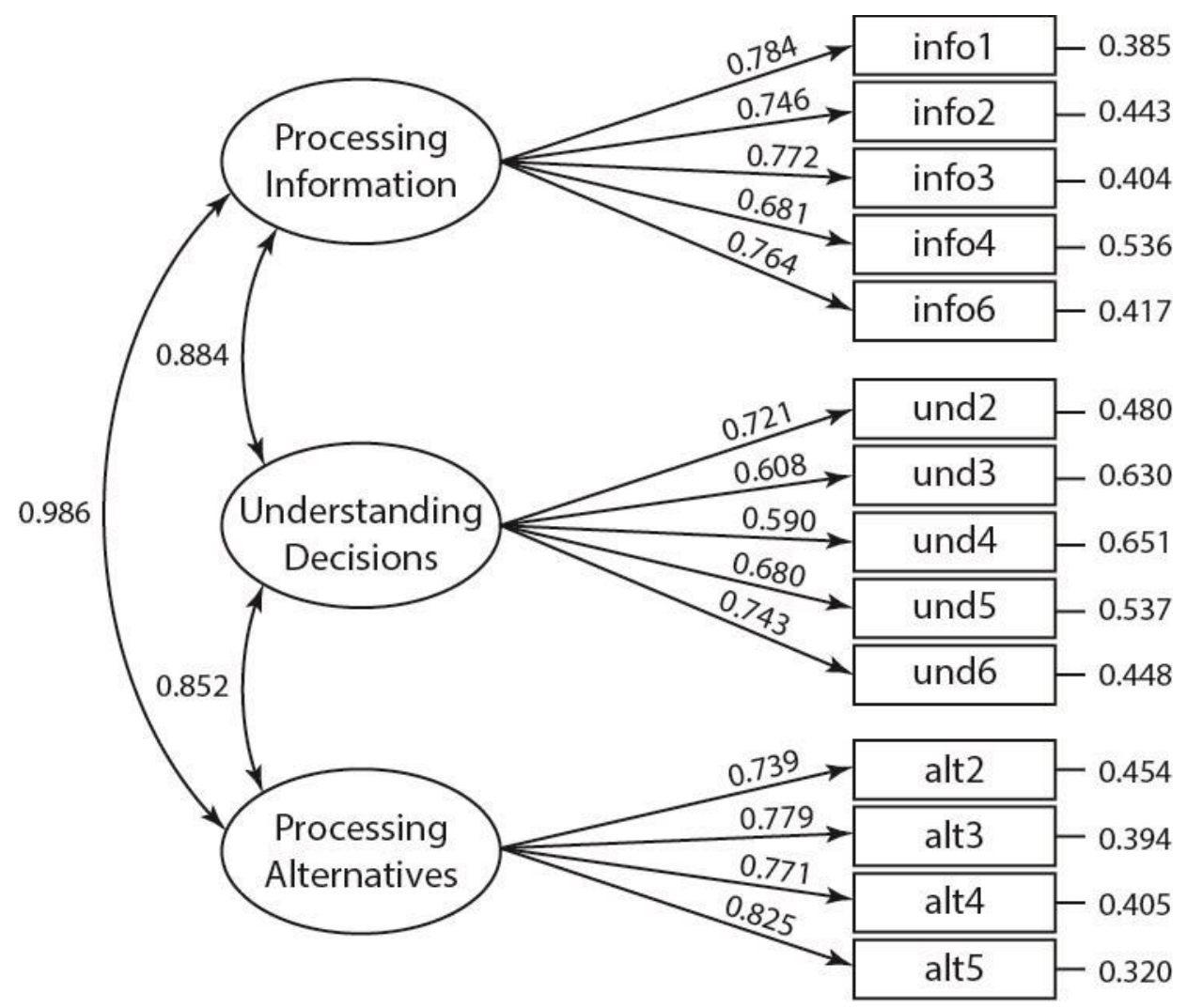

Figure 2. Completely standardized solution for first-order CFA. All values are significant at $\alpha=.001$. The model demonstrates good fit: $\chi^{2}=272.412, \mathrm{p}<.001 ;$ RMSEA $=.072 ; \mathrm{CFI}=.983 ; \mathrm{GFI}=.927$.

\section{Second-Order Confirmatory Factor Analysis}

Following the first-order analysis, a second-order CFA was conducted to test the hypothesis that the previously obtained factors could be predicted from one higher-order construct of Design Decision Making. The hypothesized model indicated that (a) responses to the decision-making instrument could be explained by three first-order factors (Processing Information, Understanding Decisions, and Processing Alternatives) and one second-order factor (Design Decision Making), (b) each item would have a nonzero loading on the first-order factor it was intended to measure and zero loadings on each the other factors, and (c) the error term for each indicator would be uncorrelated. Additionally, the second-order model also predicted that covariation between the first-order factors would be explained by their regression on the secondorder factor with an associated measurement disturbance. ${ }^{34}$ There are several benefits to a good- 
fitting second-order model including parsimony, ease of interpretation, and investigating reliability and validity. ${ }^{35,36}$ A strong motivator for testing the second-order validity of design decision making was to provide evidence that the identified factors were facets of the overall decision-making process. A well-fitting model would indicate that the questions effectively measured an overall process of decision making; variations in student responses to all of the indicators could be attributed to change in the more general design decision-making ability.

A second-order model is a more restricted form of the first-order model. ${ }^{36}$ When evaluating second-order factor structures it is recommended to consider identification of the measurement model and the structural model separately to ensure that enough information is available to produce a unique solution. ${ }^{34-36}$ With the additional parameters being estimated for the secondorder factor (the second-order factor loadings and disturbance) the model became just-identified therefore the disturbance on the Processing Information and Processing Alternatives Factors were constrained to be equal; this freed up an additional degree of freedom and allowed a unique solution to be presented. The decision to use these two factors was based on the high correlation in the first-order model. Review of the model showed that there was a good fit and conceivable parameters including a strong relationship between the second-order constructs and first-order constructs $\left(\chi^{2}=275.034, \mathrm{p}<.001 ; \mathrm{RMSEA}=.072 ; \mathrm{CFI}=.983 ; \mathrm{GFI}=.927\right)$. The revised second-order model is included in Figure 3.

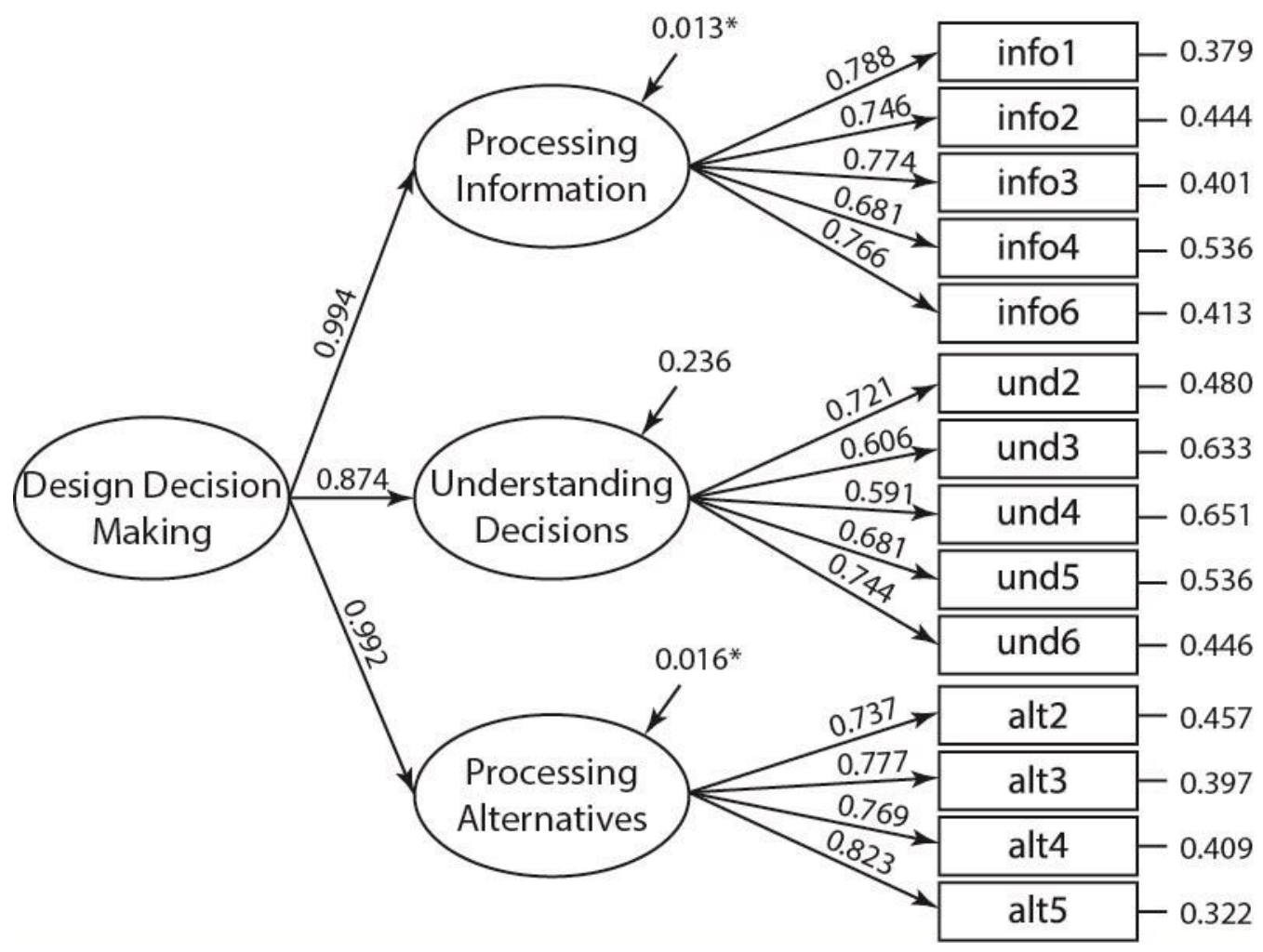

Figure 3. Completely standardized solution for second-order CFA. All values are significant at $\alpha=.001$ except marked by $(*)$. The model demonstrates good fit: $\chi^{2}=275.034, \mathrm{p}<.001 ; \mathrm{RMSEA}=.072 ; \mathrm{CFI}=.983 ; \mathrm{GFI}=.927$.

Rindskpof and Rose ${ }^{36}$ suggested that when factors have high correlation a simpler model may be preferable. With this consideration, a final comparison was made between both the first-order 
model and second-order model and a single-factor first-order model. Due to degradation of the goodness-of-fit statistics, the single-factor model was rejected $\left(\Delta \chi^{2}=84.168, \Delta d f=4, p<.005\right)$.

\section{Conclusion}

The results previously described support the initial reliability and validity of the design decisionmaking instrument. The sources, content, and expert review of the questions help provide content validity for the measurement instrument ensuring that it measures what it purports to measuregroup design decision making. The question sets have high consistency indicating that they "function together to yield a test score" (p. 7). ${ }^{37}$ Finally, the factorial validity of the instrument has been thoroughly established through EFA and multiple CFA procedures.

The model presented by this work is beneficial for understanding student design decision making. For example, our findings clarify the rich discussion on decision making by indicating that there are three reliable factors which support effective group design decision making: Processing Information, Understanding Decisions, and Processing Alternatives. Student responses across semesters show similar results supporting this model. Additionally, the three factors are highly related and the variation in these factors can be explained more generally by the efficacy of student group decision making. The second-order model statistically supports the claim that these factors are all related subsets of design decision making.

The development process of the instrument and synthesis of literature and questions about group design decision-making processes supports the use of these constructs and questions to guide decision-making instruction. The indicators align well with the overall decision process undertaken by teams and interventions designed to reinforce student decision making would prove beneficial for group decision making; these might include better processing of information, more collectively understanding group decisions, and more thoroughly considering a variety of solutions. The indicators described in this model also provide a tentative model for practitioners to evaluate group decisions. Instructors are recommended to review the instrument and work backwards to consider curriculum components that encourage these pieces of effective decision making. ${ }^{38}$ The tool provides a metric by which further instructional interventions might be evaluated: student growth in scores on one of factors would support the use of the educational strategies being evaluated.

Finally, because the second-order model fit well with the data, a simplified and more parsimonious model may be used in future work related to group decision making. Ongoing research can utilize the single second-order construct of effective decision making to assess predictive ability of the instrument. Similarly, teachers evaluating the group decision making of students can have confidence in the cohesion of the processing information, understanding decisions, and processing alternatives subscales; these three constructs work together to produce a meaningful composite score on group decision making.

\section{Recommendations}

Hoyt, Warbasse, and $\mathrm{Chu}^{39}$ suggest that evaluating validity is an "ongoing task even for established measures....For this reason, the construct-validation process resists standardizationdifferent procedures may be relevant for different constructs" (p. 774) although there are several 
commonly used forms of validity including content validity, convergent validity, discriminant validity, and criterion-related (predictive) validity. While the content validity of the group decision-making instrument is strong, as reported in our conclusions, the confirmed measurement model of design decision making should be subjected to further structural analysis to provide insight on each of these other forms of validity.

Using data collected from design thinking students, future analysis is planned to compare the group design decision results to constructs known to negatively impact decision making, such as within group conflict, to illuminate discriminant validity. Outcomes of effective decision making, such as high quality decisions and satisfaction with the decision, will also be used to show criterion validity and see if the instrument is useful for predicting future attitudes.

Positive student perceptions of effective decision making are necessary antecedents for actually using a good decision making process. However, another concern for validity is the true quality of the process. A logical step for future research would be to investigate the quality of group decision making from an outside perspective in order to substantiate the validity of self-reporting on decision process quality. This might be done through expert observations of a group decision process or artifacts from the consideration of different alternatives.

The preceding work described the development of an instrument for measuring group design decision making. The steps taken include describing the constructs being measured, generating potential items, evaluating the items through external review, and administering the instrument in two consecutive semesters of a design thinking course. Results were analyzed for factorial validity and a clear structure is present which supports the hypothesis of the researchers. The initial reliability and validity are supported and several exciting uses for the decision making instrument are presented for future research and practitioner use; it is hopeful that each of these uses will reinforce our ability to accurately measure the quality of group design decisions.

\section{References}

1. Dym, C. L., Agogino, A. M., Eris, O., Frey, D. D., \& Leifer, L. J. (2005). Engineering design thinking, teaching, and learning. Journal of Engineering Education, 94, 103-119.

2. International Technology Education Association, \& Technology for All Americans Project. (2000/2007). Standards for technological literacy: Content for the study of technology (3rd ed.). Reston, VA: International Technology Education Association. (Original work published 2000)

3. Raney, C., \& Jacoby, R. (2010, Winter). Decisions by design: Stop deciding, start designing. Rotman Magazine, 34-39.

4. ABET Engineering Accreditation Commission. (2013). Criteria for accrediting engineering programs. Baltimore: Accreditation Board for Engineering and Technology (ABET). Retrieved from: http://www.abet.org/eac-criteria-2014-2015/

5. Crismond, D. P., \& Adams, R. S. (2012). The informed design teaching and learning matrix. Journal of Engineering Education, 101(4), 738-797.

6. National Academy of Engineering. (2005). Educating the engineer of 2020: Adapting engineering education to the new century. Washington, DC: National Academies Press.

7. Pellegrino, J. W., \& Hilton, M. L. (Eds.). (2012). Education for life and work: Developing transferable knowledge and skills in the 21st century. Washington, DC: The National Academies Press. 
8. Mentzer, N. (2014). Team based engineering design thinking. Journal of Technology Education, 25(2), 52-72.

9. Hirokawa, R. Y. (1980). A comparative analysis of communication patterns within effective and ineffective decision-making groups. Communication Monographs, 47(4), 312-321. doi: 10.1080/03637758009376040

10. Atman, C. J., Cardella, M. E., Turns, J., \& Adams, R. (2005). Comparing freshman and senior engineering design processes: An in-depth follow-up study. Design Studies, 26(4), 325-357. doi: http://dx.doi.org/10.1016/j.destud.2004.09.005

11. Atman, C. J., Chimka, J. R., Bursic, K. M., \& Nachtmann, H. L. (1999). A comparison of freshman and senior engineering design processes. Design Studies, 20(2), 131-152. doi: http://dx.doi.org/10.1016/S0142694X(98)00031-3

12. Mentzer, N., Becker, K., \& Sutton, M. (in press). Engineering design thinking: High school students' performance and knowledge. Journal of Engineering Education.

13. Connolly, P., Mentzer, N., Laux, D., \& Jackson, A. (2014). Development and implementation of courses to meet the requirements of a core curriculum. Paper presented at the ASEE Illinois-Indiana Section Conference \& RosEvaluation Conference 2014, Terre Haute, IN.

14. Householder, D. L., \& Hailey, C. E. (2012). Incorporating engineering design challenges into STEM courses: National Center for Engineering and Technology Education (NCETE).

15. Usher, E. L., \& Pajares, F. (2009). Sources of self-efficacy in mathematics: A validation study. Contemporary Educational Psychology, 34(1), 89-101. doi: 10.1016/j.cedpsych.2008.09.002

16. DeVellis, R. F. (2003). Scale development : Theory and applications (2nd ed.. ed.). Thousand Oaks, Calif.: Thousand Oaks, Calif. : Sage Publications, Inc.

17. Jonassen, D. H., \& Kwon, H. I. (2001). Communication patterns in computer mediated versus face-to-face group problem solving. Educational Technology Research \& Development, 49(1), 35-51. doi: 10.1007/BF02504505

18. National Association of Colleges and Employers. (2013, October 2). Job outlook: The candidate skills/qualities employers want. Retrieved January 21, 2015, from https://www.naceweb.org/s10022013/job-outlook-skillsquality.aspx

19. Dean, J. W., Jr., \& Sharfman, M. P. (1996). Does decision process matter? A study of strategic decision-making effectiveness. Academy of Management Journal, 39(2), 368.

20. Raju, P. K., Sankar, C. S., \& Yajiong, X. (2004). A curriculum to enhance decision-making skills of technical personnel working in teams. European Journal of Engineering Education, 29(3), 437-450.

21. Schweiger, D. M., Sandberg, W. R., \& Rechner, P. L. (1989). Experiential effects of dialectical inquiry, devil's advocacy and consensus approaches to strategic decision making. Academy of Management Journal, 32(4), 745-772. doi: $10.2307 / 256567$

22. Donovan, P. (2011). "I think we should take this offline...": Conversational patterns that undermine effective decision making in action learning sets. Action Learning: Research and Practice.

23. Kelley, D., \& Kelley, T. (2013). Creative confidence: Unleashing the creative potential within us all. New York: Crown Business.

24. Evaluating drug control and system improvement projects: Guidelines for projects supported by the bureau of justice assistance. (1989). Washington, DC: The Institute.

25. Lawanto, O., \& Stewardson, G. (2013). Students' interest and expectancy for success while engaged in analysisand creative design activities. International Journal of Technology and Design Education, 23(2), 213-227. doi: 10.1007/s10798-011-9175-3

26. Adams, K., \& National Center on Education and the Economy. (2005). The sources of innovation and creativity. Washington, DC: National Center on Education and the Economy.

27. Worthington, R. L., \& Whittaker, T. A. (2006). Scale development research: A content analysis and recommendations for best practices. The Counseling Psychologist, 34(6), 806-838.

28. Christensen, C. M., Horn, M. B., \& Staker, H. (2013). Is K-12 blended learning disruptive? An introduction to the theory of hybrids. San Mateo, CA: Clayton Christensen Institute for Disruptive Innovation. Retrieved from: http://www.christenseninstitute.org/blended-learning/

29. Jackson, A., \& Mentzer, N. (2015). Teacher self-efficacy: A qualitative study of the effects of practice on graduate student instructor beliefs. Proceedings of Society for Information Technology \& Teacher Education International Conference 2015 (pp. 946-952). Chesapeake, VA: Association for the Advancement of Computing in Education (AACE).

30. Tabachnick, B. G., \& Fidell, L. S. (2007). Using multivariate statistics (5th ed.). Boston: Pearson/Allyn \& Bacon. 
31. Tinsley, H. E., \& Tinsley, D. J. (1987). Uses of factor analysis in counseling psychology research. Journal of Counseling Psychology, 34(4), 414-424. doi: 10.1037/0022-0167.34.4.414

32. Gaskin, J. (2014, September 22). Data screening. Retrieved January 13, 2015, from http://statwiki.kolobkreations.com/wiki/Data_screening

33. Hu, L. t., \& Bentler, P. (1999). Cutoff criteria for fit indexes in covariance structure analysis: Conventional criteria versus new alternatives. Structural Equation Modeling: A Multidisciplinary Journal, 6(1), 1-55. doi: $10.1080 / 10705519909540118$

34. Byrne, B. M. (1998). Structural equation modeling with lisrel, prelis, and simplis : Basic concepts, applications, and programming. Mahwah, NJ: Lawrence Erlbaum Associates.

35. Chen, F. F., Sousa, K. H., \& West, S. G. (2005). Teacher's corner: Testing measurement invariance of secondorder factor models. Structural Equation Modeling: A Multidisciplinary Journal, 12(3), 471-492. doi: $10.1207 / \mathrm{s} 15328007 \mathrm{sem} 1203 \_7$

36. Rindskopf, D., \& Rose, T. (1988). Some theory and applications of confirmatory second-order factor analysis. Multivariate Behavioral Research, 23(1), 51-67. doi: 10.1207/s15327906mbr2301_3

37. Immekus, J. C., Maller, S. J., Tracy, S., \& Oakes, W. C. (2005). Evaluating the outcomes of a service-learning based course in an engineering education program: Preliminary results of the assessment of the engineering projects in community service - epics. Paper presented at the ASEE Annual Conference \& Exposition, Portland, OR.

38. Wiggins, G. P., \& McTighe, J. (2005). Understanding by design (Expanded 2nd ed.). Alexandria, VA: Association for Supervision and Curriculum Development.

39. Hoyt, W. T., Warbasse, R. E., \& Chu, E. Y. (2006). Construct validation in counseling psychology research. The Counseling Psychologist, 34(6), 769-805.

\section{Appendix A}

How frequently did your team do each of the following throughout the final project?

(Never to Always)

1. Did your group use a well-defined process to determine factors most important to the decision? PI

2. Did your group determine factors most important to the decision? PI

3. Did your group use these factors to make your decisions? PI

4. Did your group document the factors (using a decision matrix or other tool)? PI

5. Did your group extensively look for information in making these decisions? PI

6. Did the group extensively analyze relevant information before making a decision? PI

7. Did your group collectively understand decisions? UD

8. Did your group consider a variety of alternative solutions before deciding? PA

9. Did your group look at the benefits of all alternative solutions? PA

10. Did your group look at the tradeoffs of all alternative solutions? PA

11. Did your group use a well-defined process to consider alternatives? PA

To what extent do you agree with the following statements about decision-making throughout the final project?

(Strongly Disagree to Strongly Agree)

12. Quantitative analytic techniques (such as a decision matrix) were important for our group in understanding these decisions. UD

13. The group was effective at focusing its attention on crucial information and ignoring irrelevant information when making a decision. UD

14. My team can give a clear explanation for our decisions. UD

15. I am satisfied with the way that these decisions were reached. UD

$\mathbf{P I}=$ Processing Information, $\mathbf{U D}=$ Understanding Decisions, $\mathbf{P A}=$ Processing Alternatives 